Terbit online pada laman : http://teknosi.fti.unand.ac.id/

\title{
APLIKASI DIAGNOSA KERUSAKAN SKUTER MATIK MENGGUNAKAN FUZZY MULTI-CRITERIA DECISION MAKING
}

\author{
Afandi Nur Aziz Thohari ${ }^{a *}$, Rima Dias Ramadhani ${ }^{b}$ \\ ${ }^{a}$ Prodi S1 Rekayasa Perangkat Lunak, Fakultas Teknologi Industri dan Informatika, Institut Teknologi Telkom Purwokerto,53147, Indonesia \\ ${ }^{b}$ Prodi S1 Teknik Informatika, Fakultas Teknologi Industri dan Informatika, Institut Teknologi Telkom Purwokerto,53147, Indonesia
}

\section{INFORMASI ARTIKEL}

Sejarah Artikel:

Diterima Redaksi: 15 Juli 2019

Revisi Akhir: 18 September 2019

Diterbitkan Online: 20 September 2019

\section{KATA KUNCI}

Diagnosa, Fuzzy,

MCDM,

Kerusakan,

Skuter Matik

\section{KORESPONDENSI}

E-mail: afandi@ittelkom-pwt.ac.id*

\section{A B $\mathbf{S} \mathbf{T} \mathbf{R}$ A $\mathbf{C} \mathbf{T}$}

Skuter matik (skutik) menjadi kendaraan roda dua dengan tingkat penjualan paling tinggi di Indonesia. Berdasarkan data Asosiasi Industri Sepeda motor Indonesia (AISI) tahun 2018, tercatat tingkat penjualan skutik adalah yang paling tinggi dari pada jenis sepeda motor lainnya. Namun jumlah skutik di Indonesia yang terus meningkat, ternyata tidak diimbangi dengan peningkatan jumlah bengkel skutik. Sehingga pengguna kesulitan mencari bengkel khusus untuk menangani kerusakan skutik. Penelitian ini menawarkan sebuah solusi untuk mendiagnosa dan menangani kerusakan skutik. Diagnosa kerusakan dapat dilakukan kapan saja dan dimana saja melalui smartphone. Tidak hanya sekedar menentukan kerusakan, apikasi yang dibangun juga dapat memberikan informasi mengenai penanganan solusi kerusakan. Metode yang digunakan untuk membangun aplikasi adalah Fuzzy Multi-Criteria Decision Making (FMCDM). Berdasarkan pengujian, hasil akurasi dari penerapan metode FMCDM sangat baik, yaitu 81,25 persen. Sedangkan tingkat kepuasan pengguna terhadap aplikasi FMCDM ini juga sangat puas. Hal ini dibuktikan dengan hasil survey kepuasan pengguna yang total nilai rataratanya diatas 75 persen.

\section{PENDAHULUAN}

Transportasi darat, utamanya menggunakan roda dua merupakan alternatif utama masyarakat Indonesia. Pajak kendaraan yang tidak terlalu besar dan belum adanya mass rapid transportation yang memadai, menyebabkan banyak masyarakat Indonesia memilih kendaraan roda dua sebagai alternatif utama. Diantara berbagai macam jenis kendaraan roda dua, skuter matik (skutik) merupakan kendaraan yang paling banyak disukai masyarakat.

Hal tersebut dibuktikan melalui survey Asosiasi Industri Sepeda Motor Indonesia (AISI) yang menunjukan bahwa pada tahun 2018, skutik menguasai 84,1 persen penjualan motor di Indonesia [1]. Pengguna skutik di Indonesia yang terus meningkat, ternyata tidak diimbangi dengan peningkatan jumlah bengkel skutik.
Sehingga apabila terjadi kerusakan skutik, pengguna akan sulit mencari bengkel terdekat.

Padahal untuk kerusakan-kerusakan tertentu yang tidak terlalu parah, dapat diselesaikan sendiri tanpa harus ke bengkel. Oleh karena itu dibangun aplikasi diagnosa skuter matik untuk menangani masalah-masalah kerusakan motor tanpa gigi tersebut. Sebab pada aplikasi diagnosa ini terdapat fitur konsultasi perbaikan skutik berdasar data yang pengguna masukan.

Metode yang digunakan untuk melakukan diagnosa kerusakan skutik adalah Fuzzy Multi-Criteria Decision Making (FMCDM). Melalui metode ini, pengguna dapat memasukan data yang paling mendekati dengan kerusakan yang terjadi (tidak hanya sekedar berpatokan pada ada dan tidaknya sebuah parameter kerusakan). Metode FMCDM menerapkan konsep sistem pendukung 
keputusan, dimana terdapat identifikasi gejala/kriteria untuk mendapatkan alternatif keputusan[2]. Adapun beberapa penelitian yang menggunakan FMCDM adalah sebagai berikut.

Penelitian yang dilakukan oleh [3] yang membuat sistem pendukung keputusan pemilihan smartphone menggunakan FMCDM. Hasil yang diperoleh adalah rekomendasi smartphone yang sesuai dengan kebutuhan pengguna. Kemudian penelitian yang dilakukan oleh [4] yang membuat sistem pendukung keputusan dengan metode FMCDM untuk menentukan kelinci pedaging unggul. Lalu yang berikutnya penelitian yang dilakukan oleh [5] tentang pemilihan wilayah aternatif terbaik dengan metode FMCDM. Sistem yang dibangun dapat memenuhi standar dalam menentukan lokasi yang strategis. Terakhir penelitian yang dilakukan oleh [6] mengenai penerapan FMCDM untuk diagnosa penyakit tropis. Hasilnya penyakit demam berdarah merupakan hasil penyakit optimal yang diperoleh

Pada penelitian ini, FMCDM diterapkan untuk menentukan kerusakan skutik. Perbedaan dengan beberapa penelitian yang telah disebutkan terletak pada platform yang digunakan. Pada penelitian ini pengguna dapat mengakses melalui platform mobile. Alasan dipakainya plaform mobile adalah karena menurut survey Asosiasi Pengguna Jasa Internet Indonesia (APJII) tahun 2017 pengguna smartphone di Indonesia mencapai lebih dari 70 persen di daerah urban [7]. Kelebihan penggunaan smartphone adalah pengguna dapat melakukan melakukan diagnosa kerusakan skutik dimana saja dan kapan saja. Adapun platform mobile yang digunakan baru terbatas untuk sistem operasi android.

\section{METODE}

\subsection{Metode Pengumpulan Data}

Pengambilan data dilakukan dengan cara melalukan wawancara kepada pakar. Wawancara dilakukan untuk mendapatkan data kerusakan, serta penyebab kerusakan skuter matik. Selain itu agar pemilik motor mengetahui penanganan kerusakan skutik maka di ambil juga data solusi penganganan kerusakan skutik.

\subsection{Populasi dan Sampel}

Populasi data penelitian ini adalah daftar kerusakan, gejala, dan solusi. Populasi data diambil dari hasil wawancara teknisi bengkel yamaha nusantara motor yang terletak di jalan Overste Isdiman, No. 51, Purwokerto, Jatiwinangun, Purwokerto Lor. Sehingga sample data yang dipakai adalah motor skutik dengan merk yamaha.

\subsection{Alat Penelitian}

Penerapan metode MCDM dilakukan dengan bahasa pemrograman PHP. Agar tampilan dari program user friendly maka digunakan framework bootstrap. Kemudian pembuatan aplikasi mobile dilakukan menggunakan lingkungan pengembangan android studio dengan bahasa java.

\subsection{Arsitektur Sistem}

Sistem yang dibangun berjalan pada dua platform yaitu web dan mobile. Tujuan dibangun versi mobile adalah untuk memudahkan user dalam mengidentifikasi kerusakan skutik. Sebab dengan menggunakan smartphone, akses sistem dapat dilakukan dimana saja dan kapan saja. Arsitektur dari sistem yang dibangun ditunjukan pada Gambar 1.

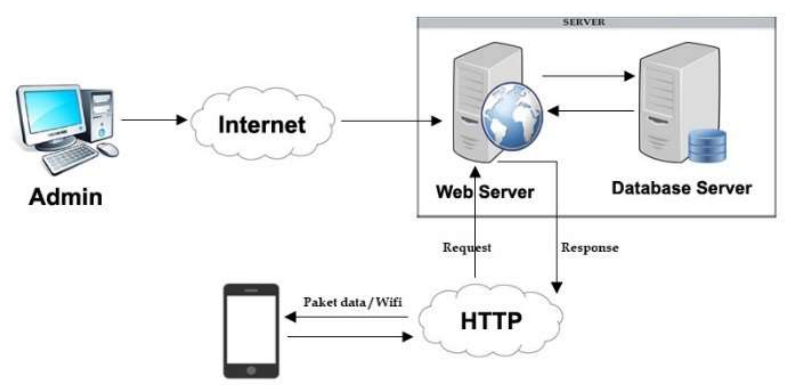

Gambar 1. Arsitektur Sistem

Gambar 1 menunjukan bahwa akses dari sistem dapat dilakukan melalui web dan smartphone melalui internet. Admin dapat menambah alternatif kerusakan, gejala kerusakan dan parameter himpunan fuzzy. Semua berkas yang digunakan untuk membangun aplikasi seperti skrip kode dan gambar disimpan di web server. Sedangkan data gejala, alternatif dan himpunanhimpunan fuzzy disimpan di database server. Antara web server dan database server saling terhubung untuk menampilkan informasi. Kemudian dibuat aplikasi webview agar informasi yang ditampilkan dapat mengikuti layar dari smartphone.

\subsection{Perancangan Sistem}

Sebelum aplikasi dibangun, dilakukan perancangan sistem dengan membuat diagram use case dan Entity Relationalship Diagram (ERD). Diagram use case digunakan untuk mengetahui alur kerja dari aktor yang menggunakan sistem, sedangkan ERD digunakan untuk mengetahui aliran data dan tabel-tabel yang diperlukan. Adapun diagram use case yang digunakan pada penelitian ini ditunjukan pada Gambar 2.

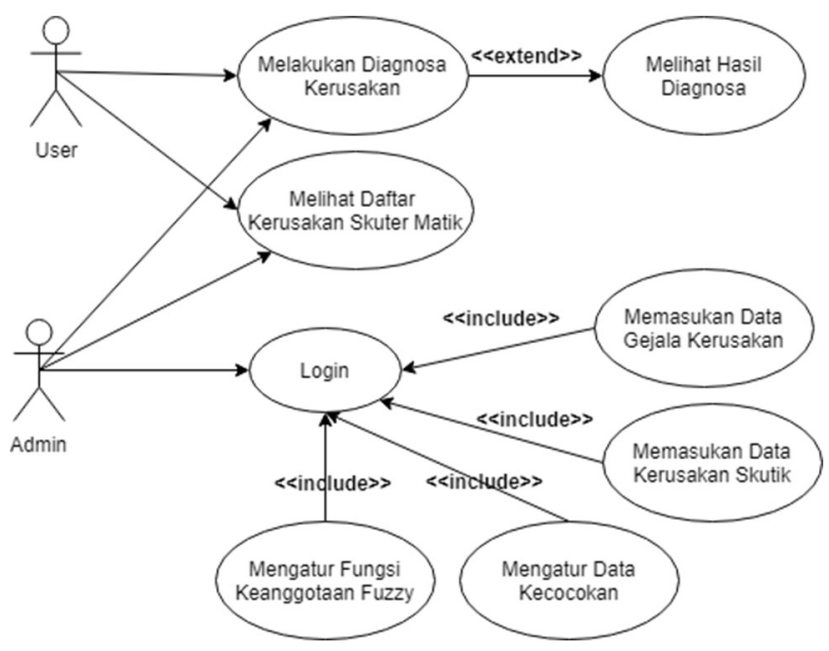

Gambar 2. Diagram Use Case Aplikasi Diagnosa Kerusakan Skutik

Diagram use case pada Gambar 2 menunjukan bahwa terdapat dua aktor yang terlibat dalam penggunaan aplikasi yaitu $u$ ser dan admin. User tanpa harus login dapat melakukan diagnosa kerusakan skutik dan juga melihat hasil diagnosa yang diproses oleh sistem. Sedangkan admin memiliki hak akses yang lebih banyak dibanding user. Hak akses yang diperoleh admin adalah 
mampu untuk menambah data gejala dan kerusakan dari skutik. Selain itu juga memiliki wewenang untuk mengatur fungsi keanggotan dan kecocokan dari himpunan fuzzy. Tentunya untuk mengatur data-data tersebut admin harus melalui proses login terlebih dahulu.

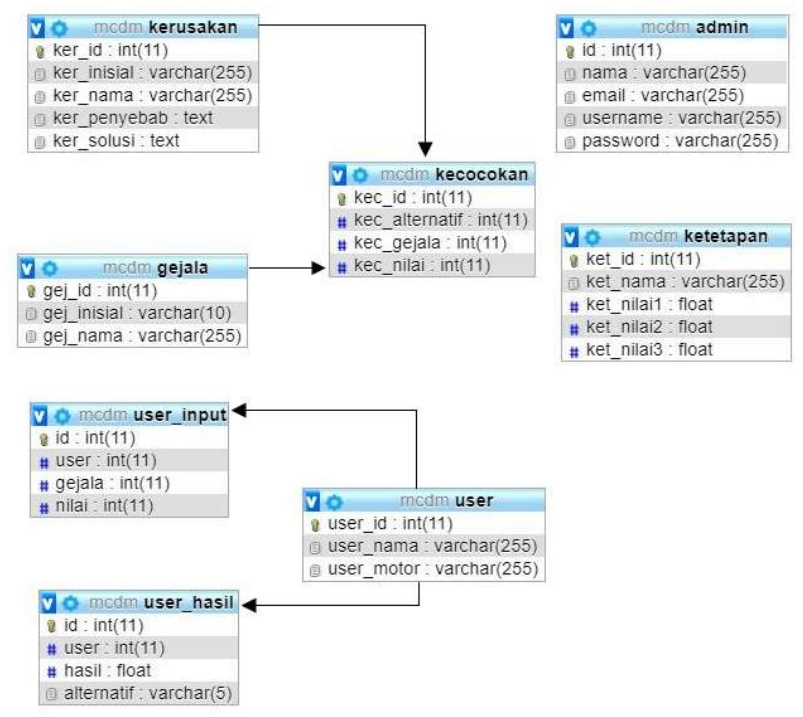

Gambar 3. ERD Aplikasi Diagnosa Kerusakan Skutik

Sedangkan ERD dari aplikasi diagnosa kerusakan skutik ditujukan pada Gambar 3. Terdapat 8 tabel yang digunakan pada aplikasi yang dibangun. Tabel kecocokan memiliki korelasi dengan tabel kerusakan dan gejala. Sebab pada tabel kecocokan terdapat field yang menjadi foreign key dari tabel gejala dan kerusakan. Sedangkan pada tabel user terdapat id yang menjadi foreign key di tabel user_input dan tabel user_hasil.

\subsection{Logika Fuzzy}

Sebelum adanya teori logika fuzzy, sebuah sistem memiliki logika yang tegas yaitu nilai benar dan salah [8][9]. Kemudian setelah masuknya teori fuzzy muncul sebuah nilai kesamaaran (fuzzyness) antara benar dan salah. Fuzzy merupakan salah satu cabang dari kecerdasan buatan yang banyak dikembangkan karena mempunyai keunggulan dalam penyelesaian masalah yang mengandung ketidakpastian, dan kebenaran pasrsial [10]. Logika fuzzy memiliki anggota-anggota himpunan yang direpresentasikan dalam sebuah fungsi. Ada beberapa fungsi yang dapat digunakan untuk menunjukan keanggotaan fuzzy.

Fungsi keanggotaan digambarkan dalam bentuk kurva yang menunjukan pemetaan titik-titik input data ke dalam nilai keanggotaannya. Pada penelitian ini digunakan representasi kurva segitiga untuk menentukan kriteria anggotanya. Gambar 4 adalah representasi kurva segitiga.

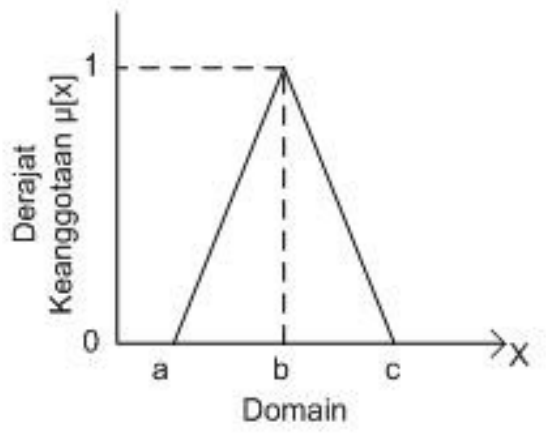

Gambar 4. Kurva Segitiga

Fungsi Keanggotaan :

$$
\mu[\mathrm{x}]=\left\{\begin{array}{cl}
0 & x \leq \text { a atau } x \geq c \\
(b-a) /(x-a) & \\
(b-x) /(c-b)
\end{array}\right\} \quad \begin{aligned}
& a \leq x \leq b \\
& b \leq x \leq c
\end{aligned}
$$

\subsection{Multi-Criteria Decision Making}

Multi-Criteria Decision Making (MCDM) adalah salah satu metode yang dapat digunakan untuk mengambil sebuah keputusan berdasarkan alternatif yang memiliki tingkat prioritas berbeda untuk dijadikan bahan pertimbangan. Metode ini cocok digunakan untuk menentukan keputusan berdasarkan data yang bersifat kualitatif dengan alternatif yang memiliki banyak kriteria. Langkah-langkah yang harus ditempuh untuk mengimplementasikan MDCM telah dilakukan oleh beberapa peneliti. Diantaranya yang dilakukan oleh [11] dan [12] dalam [13]. Langkah-langkah yang dilakukan dalam penelitian tersebut adalah representasi masalah, evaluasi himpunan fuzzy, serta seleksi alternatif yang optimal.

\subsubsection{Representasi Masalah}

Terdapat 3 kegiatan yang dilakukan pada tahap ini, yaitu :

a. Identifikasi tujuan dan kumpulan alternatif keputusannya.

b. Identifikasi kumpulan kriteria

c. Membangun struktur hirarki dari masalah berdasarkan pertimbangan-pertimbangan tertentu

\subsubsection{Evaluasi himpunan fuzzy}

Terdapat 3 kegiatan yang dilakukan pada tahap ini, yaitu :

a. Memilih himpunan rating untuk bobot-boot kriteria dan derajat kecocokan

b. Mengevaluasi bobot-bobot kriteria dan derajat kecocokan setiap alternatif dengan kriterianya

c. Mengagregasikan bobot-bobot kriteria dan derajat kecocokan setiap alternatif dengan kriterianya

Terdapat beberapa metode yang dapat digunakan untuk mengagregasikan hasil keputusan para pengambil keputusan. Namun dari beberapa metode tersebut, metode mean yang paling banyak dipakai. Penerapan metode mean adalah menghitung rata-rata dari nilai kecocokan setiap kriteria[14][15]. Adapun metode mean dirumuskan seperti persamaan (1), dimana $F_{i}$ adalah nilai mean, $S_{i t}$ adalah nilai kecocokan kriteria, dan $W_{i t}$ adalah bobot.

$F_{i}=\frac{1}{k}\left[\left(S_{t 1} \cdot W_{t 1}\right)+\left(S_{t 2} \cdot W_{t 2}+\ldots .+\left(S_{t k} \cdot W_{t k}\right.\right.\right.$ 
Mensubstitusikan $S_{i t}$ dan $W_{t}$ dengan bilangan fuzzy segitiga, yaitu $S_{i t}=\left(O_{i t}, P_{i t}, Q_{i t}\right)$; dan $W_{i t}=\left(a_{t}, b_{t}, c_{t}\right)$; maka $F_{i}$ dapat didekati sebagai berikut

$F_{i} \approx\left(Y_{i}, Q_{i}, Z_{i}\right)$

dengan :

$Y_{i}=\frac{1}{k} \sum_{t-1}^{k}\left(o_{i t}, a_{i}\right)$

$Q_{i}=\frac{1}{k} \sum_{t-1}^{k}\left(p_{i t}, b_{i}\right)$

$Z_{i}=\frac{1}{k} \sum_{t-1}^{k}\left(q_{i t}, c_{i}\right)$

dimana, $\mathrm{i}=1,2,3, \ldots \mathrm{n}$

\subsubsection{Seleksi Alternatif yang Optimal}

Terdapat 2 kegiatan yang dilakukan pada bagian ini, yaitu :

a. Memprioritaskan alternatif keputusan berdasarkan hasil agregasi

Prioritas dari hasil agregasi dibutuhkan dalam rangka proses perangkingan alternatif keputusan. Karena hasil agregasi ini direpresentasikan dengan menggunakan bilangan fuzzy segitiga, maka dibutuhkan metode perangkingan untuk bilangan fuzzy segitiga. Salah satu metode yang dapat digunakan adalah metode nilai total integral. Misalkan F adalah bilangan fuzzy segitiga, $F=(a, b, c)$, maka nilai total integral dapat dirumuskan sebagai berikut:

$I_{T}^{a}(F)=\left(\frac{1}{2}\right)(\alpha c+b+(1-\alpha) a)$

Nilai a adalah indeks keoptimisan yang merepresentasikan derajat keoptimisan bagi pengambil keputusan $(0 \leq \alpha \leq 1)$.

Apabila nilai $\alpha$ semakin besar mengindikasikan bahwa derajat keoptimisannya semakin besar.

b. Memilih alternatif keputusan dengan prioritas tertinggi sebagai alternatif optimal

\section{HASIL}

\subsection{Implementasi Fuzzy MCDM}

\subsubsection{Representasi Masalah}

Pada tahap ini ditentukan mengenai alternatif (hasil) yang terjadi setelah diberikan gejala-gejala kerusakan skutik. Rincian dari alternatif dan gejala yang direpresentasikan dalam sebuah inisial sebagai berikut.

a. Terdapat 6 kerusakan skutik yang direpresentasikan dengan $\mathrm{A}=\{\mathrm{A} 1, \mathrm{~A} 2, \mathrm{~A} 3, \mathrm{~A} 4, \mathrm{~A} 5, \mathrm{~A} 6\}$. Inisial A1 adalah
Accu/Baterai, A2 adalah Piston, A3 adalah Karbulator, A4 adalah V-Belt, A5 adalah Busi, A6 adalah Filter Udara.

b. Kemudian terdapat 19 gejala kerusakan skutik yang direpresentasikan dengan $\mathrm{G}=\{\mathrm{G} 1, \mathrm{G} 2, \mathrm{G} 3, \mathrm{G} 4, \mathrm{G} 5, \mathrm{G} 6, \mathrm{G} 7$, G8, G9, G10, G11, G12, G13, G14, G15, G16, G17, G18, G19\}. Data keterangan gejalan ditunjukan pada Tabel 1.

Tabel 1. Daftar Gejala Kerusakan Skutik

\begin{tabular}{lll}
\hline No & Inisial & \multicolumn{1}{c}{ Nama Gejala Kerusakan } \\
\hline 1 & G1 & Tarikan kurang kencang \\
\hline 2 & G2 & Sepeda motor sulit hidup \\
\hline 3 & G3 & Sepeda motor sering mati tiba-tiba \\
\hline 4 & G4 & $\begin{array}{l}\text { Sering terjadi ledakan pada knalpot saat gas } \\
\text { di turunkan }\end{array}$ \\
\hline 5 & G5 & Sepeda motor tersendat saat jalan \\
\hline 6 & G6 & Karburator sering banjir \\
\hline 7 & G7 & Mesin cepat panas \\
\hline 8 & G8 & Suara mesin kasar \\
\hline 9 & G9 & Starter elektrik tidak berfungsi \\
\hline 10 & G10 & Lampu utama redup \\
\hline 11 & G11 & $\begin{array}{l}\text { Lampu indikator / sin / rem tidak menyala } \\
\text { saat mesin mati }\end{array}$ \\
\hline 12 & G12 & Suara klakson lemah \\
\hline 13 & G13 & Keluar asap putih dari knalpot \\
\hline 14 & G14 & Mesin agak bergetar saat di hidupkan \\
\hline 15 & G15 & Busi sering rusak \\
\hline 16 & G16 & Minyak boros berlebihan \\
\hline 17 & G17 & Saat di gas, roda belakang tidak berputar \\
\hline 18 & G18 & $\begin{array}{l}\text { Ada suara berisik pada bagian mesin sebelah } \\
\text { kiri }\end{array}$ \\
\hline 19 & G19 & Mesin sepeda motor tidak hidup sama sekali \\
\hline & &
\end{tabular}

\subsubsection{Evaluasi Himpunan Fuzzy}

a. Setiap gejala yang dimasukan memiliki masing-masing bobot kepentingan. Adapun representasi dari bobot (W) adalah Sangat Rendah, Rendah, Sedang, Tinggi, dan Sangat Tinggi. Tabel 2. Fungsi Keanggotaan

\begin{tabular}{llrrr}
\hline No & Nama & \multicolumn{1}{c}{ Nilai 1 } & Nilai 2 & \multicolumn{1}{c}{ Nilai 3 } \\
\hline 1 & Sangat Rendah & 0 & 0.25 & 0.25 \\
\hline 2 & Rendah & 0.25 & 0.5 & 0.5 \\
\hline 3 & Sedang & 0.5 & 0.5 & 0.75 \\
\hline 4 & Tinggi & 0.75 & 0.75 & 1 \\
\hline 5 & Sangat Tinggi & 1 & 1 & 1 \\
\hline
\end{tabular}

Tabel 3. Data Kecocokan Gejala dengan Alternatif

\begin{tabular}{|c|c|c|c|c|c|c|c|c|c|c|c|c|c|c|c|c|c|c|c|}
\hline \multirow{2}{*}{$\begin{array}{l}\text { Alter } \\
\text { natif }\end{array}$} & \multicolumn{19}{|c|}{ Rating Kecocokan } \\
\hline & G1 & G2 & G3 & G4 & G5 & G6 & G7 & G8 & G9 & G10 & G11 & G12 & G13 & G14 & G15 & G16 & G17 & G18 & G19 \\
\hline A1 & SR & SR & SR & SR & SR & SR & SR & SR & ST & ST & ST & ST & SR & SR & SR & SR & SR & SR & SR \\
\hline A2 & $\mathrm{T}$ & $\mathrm{T}$ & SR & SR & $\mathrm{R}$ & SR & $\mathrm{T}$ & ST & SR & SR & SR & SR & ST & SR & SR & SR & SR & SR & ST \\
\hline A3 & ST & ST & $\mathrm{R}$ & ST & ST & SR & SR & SR & SR & SR & SR & SR & SR & SR & SR & ST & SR & SR & ST \\
\hline A4 & ST & SR & SR & SR & ST & SR & SR & SR & SR & SR & SR & SR & SR & SR & SR & SR & ST & ST & SR \\
\hline A5 & $\mathrm{T}$ & $\mathrm{T}$ & $\mathrm{T}$ & ST & ST & SR & SR & SR & SR & SR & SR & SR & SR & SR & SR & SR & SR & SR & ST \\
\hline A6 & ST & ST & $\mathrm{T}$ & SR & SR & SR & SR & SR & SR & SR & SR & SR & SR & SR & $\mathrm{T}$ & SR & SR & SR & SR \\
\hline
\end{tabular}

b. Fungsi keanggotaan untuk setiap elemen direpresentasikan menggunakan bilangan fuzzy segitiga yang ditunjukan pada Tabel 2 . c. Alternatif keputusan yang diberikan sistem tergantung pada gejala dan bobot kriteria yang dimasukan oleh user. Data kecocokan setiap kriteria pada masing-masing alternatif ditunjukan pada Tabel 3. 
d. Contoh kasus yang diberikan berdasarkan inputan dari user (Rating Kepentingan) ditunjukan pada Tabel 4.

Tabel 4. Rating Kepentingan

\begin{tabular}{lll}
\hline No & Alternatif & Rating Kepentingan \\
\hline 1 & G1 & Sangat Tinggi \\
\hline 2 & G2 & Sangat Tinggi \\
\hline 3 & G3 & Tinggi \\
\hline 4 & G4 & Sangat Rendah \\
\hline 5 & G5 & Sangat Rendah \\
\hline 6 & G6 & Sangat Rendah \\
\hline 7 & G7 & Sangat Rendah \\
\hline 8 & G8 & Sangat Rendah \\
\hline 9 & G9 & Rendah \\
\hline 10 & G10 & Sangat Rendah \\
\hline 11 & G11 & Sangat Rendah \\
\hline 12 & G12 & Rendah \\
\hline 13 & G13 & Sangat Rendah \\
\hline 14 & G14 & Sangat Rendah \\
\hline 15 & G15 & Sangat Tinggi \\
\hline 16 & G16 & Sangat Rendah \\
\hline 17 & G17 & Sangat Rendah \\
\hline 18 & G18 & Sangat Rendah \\
\hline 19 & G19 & Sangat Rendah \\
\hline
\end{tabular}

e. Menghitung nilai kecocokan terhadap setiap kriteria dengan mensubsitusikan bilangan fuzzy segitiga ke setiap alternatif. Proses perhitungan nilai kecocokan menggunakan persamaan (3), (4), dan (5). Hasil perhitungan ditunjukan pada Tabel 5.

Tabel 5. Nilai Kecocokan Setiap Alternatif

\begin{tabular}{cccc}
\hline \multirow{2}{*}{ Alternatif } & \multicolumn{3}{c}{ Indeks Kecocokan Fuzzy } \\
\cline { 2 - 4 } & $Y_{i}$ & $Q_{i}$ & $Z_{i}$ \\
\hline $\mathrm{A} 1$ & 0.02631 & 0.16447 & 0.16776 \\
\hline $\mathrm{A} 2$ & 0.07894 & 0.19736 & 0.23026 \\
\hline $\mathrm{A} 3$ & 0.11513 & 0.23355 & 0.24013 \\
\hline $\mathrm{A} 4$ & 0.05263 & 0.17434 & 0.17763 \\
\hline $\mathrm{A} 5$ & 0.10855 & 0.20723 & 0.25657 \\
\hline $\mathrm{A} 6$ & 0.17434 & 0.23026 & 0.26644 \\
\hline
\end{tabular}

\subsubsection{Seleksi Alternatif yang Optimal}

Langkah terakhir untuk pengambilan keputusan kerusakan skuter matik adalah dengan menghitung nilai totoal integral untuk setiap alternatif. Caranya adalah dengan mensubsitusikan indeks kecocokan fuzzy pada tabel 5 ke persamaan (6). Kemudian ditentuakan derajat keoptimisan $(\alpha)=0$ (tidak optimis), $\alpha=0.5$ (optimis), dan $\alpha=1$ (sangat optimis). Nilai total integral setiap alternatif ditunjukan pada Tabel 6 .

Tabel 6. Nilai Total Integral Setiap Alternatif

\begin{tabular}{cccc}
\hline \multirow{2}{*}{ Alternatif } & \multicolumn{3}{c}{ Nilai Total Integral } \\
\cline { 2 - 4 } & 0 & 0.5 & 1 \\
\hline A1 & 0.09539 & 0.13075 & 0.16611 \\
\hline A2 & 0.13815 & 0.17598 & 0.21381 \\
\hline A3 & 0.17434 & 0.20559 & 0.23684 \\
\hline A4 & 0.11348 & 0.14473 & 0.17598 \\
\hline A5 & 0.15789 & 0.19490 & 0.23190 \\
\hline A6 & 0.20230 & 0.22532 & 0.24835 \\
\hline
\end{tabular}

Berdasarkan data pada Tabel 6, diketahui bahwa nilai total integral paling besar terdapat pada alternatif A6. Sehingga berdasarkan perhitungan menggunakan FMCMD tersebut, kerusakan skutik disebabkan oleh filter udara.

\subsection{Tampilan antar muka sistem}

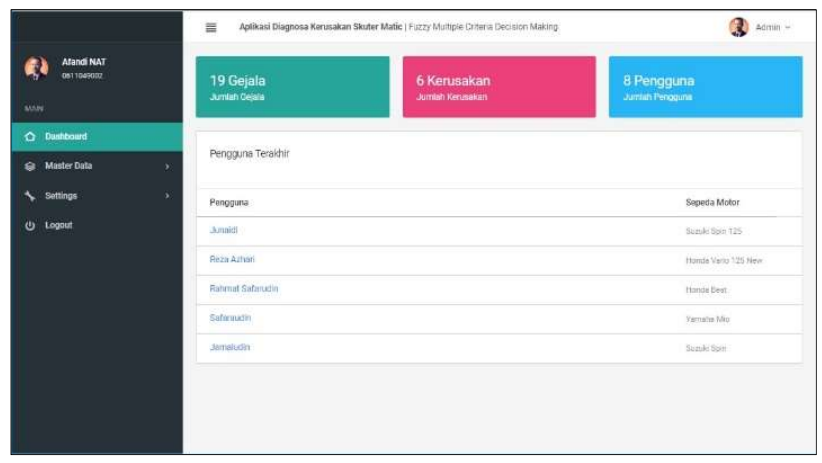

Gambar 5. Tampilan awalan halaman admin

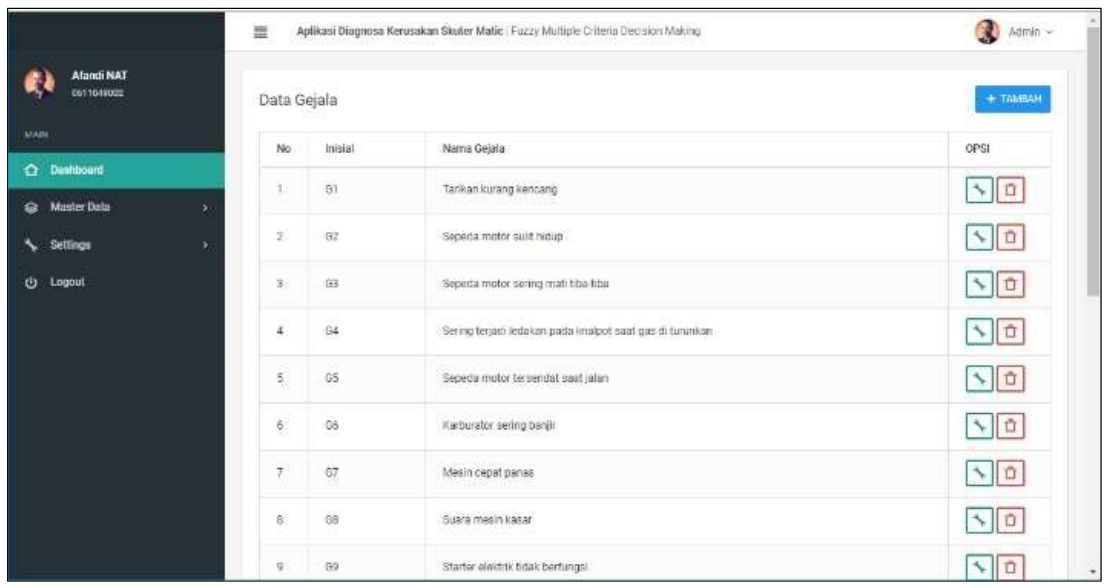

Gambar 6. Tampilan menu perubahan gejala kerusakan skutik

Menu admin digunakan untuk melakukan pengaturan dan monitoring data dari sistem. Halaman awal dari menu admin ditunjukan pada Gambar 5. Ketika user masuk sebagai admin maka akan memiliki hak akses untuk melakukan perubahan rule dari sistem MCDM yang dibangun. Perubahan-perubahan 
tersebut diantaranya dapat melakukan tambah, edit, dan hapus gejala dari kerusakan skutik, seperti ditunjukan pada Gambar 6.

Selain itu seorang admin juga dapat mengatur alternatif kerusakan skutik, mengatur fungsi keanggotaan fuzzy, dan mengatur data kecocokan tiap alternatif. Agar dapat masuk ke menu admin, seorang user harus login terlebih dahulu. Selanjutnya hasil perubahan yang dilakukan admin dapat dirasakan oleh user melalui aplikasi smartphone. User dapat melakukan diagnosa kerusakan skutik melalui smartphone mereka.

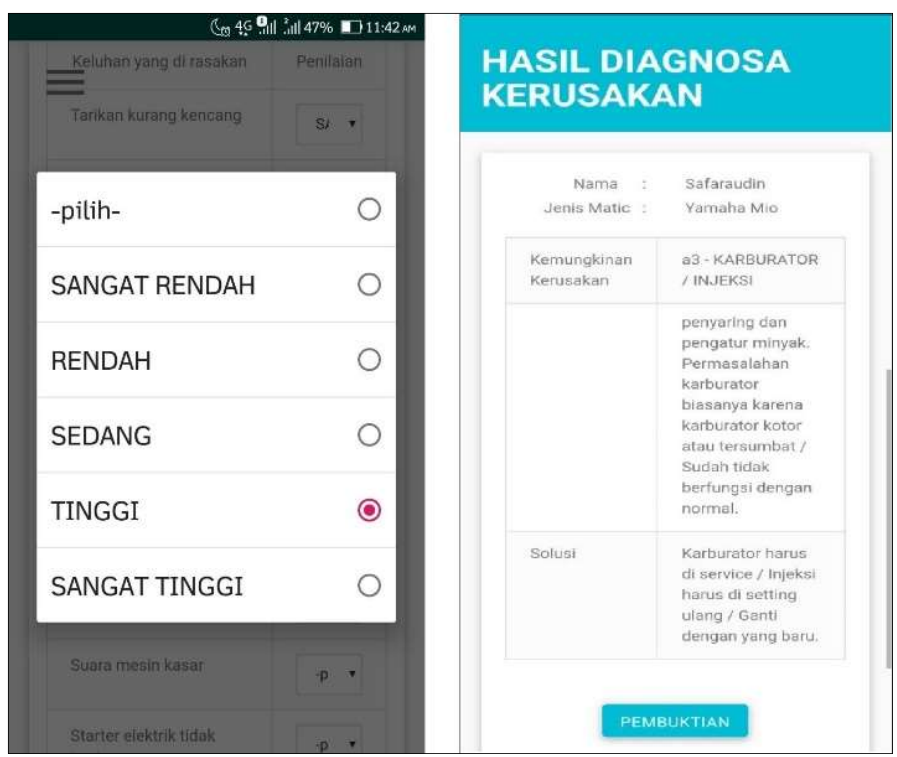

Gambar 7. Tampilan Antarmuka pada Smartphone

Sistem diagnosa kerusakan skutik dapat diakses melalui smartphone. Namun hanya untuk smartphone dengan sistem operasi android. Tampilan antarmuka sistem akan menyesuaikan ukuran layar smartphone, sehingga user akan mudah untuk menggunakannya. Tampilan masukan user dan hasil diagonosa kerusakan skutik ditunjukan pada Gambar 7.

\section{PEMBAHASAN}

\subsection{Pengujian Akurasi Sistem}

Pengujian akurasi sistem dilakukan dengan cara membandingkan hasil diagnosa yang dilakukan sistem dengan data real dari kerusakan skuter matik. Jumlah data uji yang diberikan sejumlah 32. Data tersebut diperoleh dari hasil observasi di bengkel yamaha di jalan overste isdiman no.51 Purwokerto. Hasil pengujian tingkat akurasi sistem menggunakan fuzzy MCDM ditunjukan pada Tabel 7.

Tabel 7. Pengujian Akurasi Sistem

\begin{tabular}{llccc}
\hline No & Kerusakan & Benar & Salah & Total \\
\hline 1 & Accu / Baterai & 3 & 1 & 4 \\
\hline 2 & Piston & 2 & 1 & 3 \\
\hline 3 & Karburator/Injeksi & 5 & 1 & 6 \\
\hline 4 & V-Belt/Tali Kipas & 4 & 1 & 5 \\
\hline 5 & Busi & 8 & 0 & 8 \\
\hline 6 & Filter Udara & 4 & 2 & 6 \\
\hline & Total & 26 & 6 & 32 \\
\hline & Akurasi & $81,25 \%$ & $18,75 \%$ & \\
\hline & & &
\end{tabular}

Berdasarkan data pada Tabel 7, diketahui bahwa tingkat akurasi dari sistem menggunakan metode fuzzy MCDM adalah 81,25\%. Hasil tersebut menunjukan bahwa sistem sudah dapat digunakan untuk menidentifikasi kerusakan skuter matik

\subsection{Pengujian Kemudahan Antarmuka Aplikasi}

Pengukuran tingkat kepuasan penggunaan aplikasi dilakukan dengan menggunakan kuesioner dengan melibatkan 30 responden. Seluruh responden berasal dari mahasiswa S1 Rekayasa Perangkat Lunak IT Telkom Purwokerto, tempat penulis mengabdikan ilmunya. Total keseluruhan pertanyaan adalah 25 dengan skala satu (1) sampai 5 (lima). Alternatif jawaban sangat setuju diberi skor 5, sedangkan skor yang paling rendah yaitu 1, apabila alternatif jawaban resonden sangat tidak setuju. Pengolahan hasil kuesioner dilakukan menggunakan skala likert. Adapaun hasil setelah dilakukan perhitungan dengan skala likert adalah sebagai berikut.

Tabel 8. Hasil Kepuasan Pengguna Aspek Informativeness

\begin{tabular}{lll}
\hline No & Informativeness & Total \\
\hline 1 & $\begin{array}{l}\text { Sistem yang ada menghasilkan informasi } \\
\text { yang akurat }\end{array}$ & $73 \%$ \\
\hline 2 & $\begin{array}{l}\text { Informasi yang dihasilkan selalu sesuai } \\
\text { dengan kenyataan atau kejadian yang }\end{array}$ & $71 \%$ \\
& $\begin{array}{l}\text { sesungguhnya terjadi } \\
\text { Sistem yang ada menyediakan informasi }\end{array}$ & $76 \%$ \\
\hline 3 & yang sesuai dengan kebutuhan Anda \\
\hline 5 & $\begin{array}{l}\text { Sistem menyediakan informasi yang detail } \\
\text { relevan }\end{array}$ & $79 \%$ \\
\hline
\end{tabular}


Berdasarkan Tabel 8 dapat disimpulkan bahwa sistem sudah baik dalam memberikan informasi terkait penjelasan diagnosa kerusakan skuter matik. Hal ini ditunjukan dengan total rata-rata kepuasan yaitu $75 \%$. Informasi yang diberikan sistem sudah detail, hal itu ditunjukan dengan total penilaian responden sebesar $79 \%$.

Tabel 9. Hasil Kepuasan Pengguna Aspek Format Informasi

\begin{tabular}{lll}
\hline No & Information Format & Total \\
\hline 1 & $\begin{array}{l}\text { Informasi yang disajikan jelas untuk } \\
\text { dimengerti }\end{array}$ & $76 \%$ \\
\hline 2 & $\begin{array}{l}\text { Keluaran (report) yang disajikan dalam } \\
\text { sistem yang sesuai dengan kebutuhan }\end{array}$ & $73 \%$ \\
\hline 3 & Tata letaknya (display) mudah dibaca & $80 \%$ \\
\hline
\end{tabular}

Penilaian format informasi yang disajikan pada Tabel 9 menunjukan bahwa pengunjung dapat dengan mudah dan jelas dalam mendapatkan informasi terkait hasil diagnosa. Tata letak komponen graphical user interface (GUI) dari aplikasi sudah sangat baik. Hal ini ditunjukan dengan persentase hasil penilaian responden sebesar $80 \%$.

Tabel 10. Hasil Kepuasan Pengguna Aspek Kemudahan Penggunaan

\begin{tabular}{lll}
\hline No & Easy of Use & Total \\
\hline 1 & $\begin{array}{l}\text { Tampilan menu pada sistem ini mudah } \\
\text { untuk dikenali }\end{array}$ & $81 \%$ \\
\hline 2 & Sistem yang ada mudah dipahami & $79 \%$ \\
\hline 3 & Sistem yang ada mudah digunakan & $79 \%$ \\
\hline 4 & Sistem yang ada mudah dipelajari & $79 \%$ \\
\hline 5 & Sistem memiliki proses input yang mudah & $80 \%$ \\
\hline
\end{tabular}

Hasil penilaian kemudahan penggunaan aplikasi ditunjukan pada Tabel 10. Berdasarkan Tabel 10 dapat disimpulkan bahwa aplikasi yang dibangun dapat dengan mudah digunakan dan dipelajari oleh pengguna. Hal itu dibuktikan dengan rata-rata total kepuasan reponden terkait kemudahan penggunaan apliksi, yaitu diatas $75 \%$

Tabel 11. Hasil Kepuasan Pengguna Aspek Timeliness

\begin{tabular}{lll}
\hline No & Timeliness & Total \\
\hline 1 & $\begin{array}{l}\text { Informasi (hasil diagnosa) yang diberikan } \\
\text { kepada Anda adalah informasi yang ada } \\
\text { dalam sistem pendukung keputusan yang } \\
\text { diproses dengan baik }\end{array}$ & \\
\hline 2 & $\begin{array}{l}\text { Sistem ini memiliki kecepatan respon yang } \\
\text { baik }\end{array}$ & $79 \%$ \\
\hline 3 & $\begin{array}{l}\text { Seluruh fungsi yang dijalankan pada sistem } \\
\text { bekerja dengan baik }\end{array}$ & $77 \%$ \\
\hline
\end{tabular}

Pada sebuah sistem, keberhasilan mengeksekusi data menjadi sebuah informasi adalah hal yang utama. Tabel 11 adalah hasil penilaian responden terhadap keberhasilan dan kecepatan menampilkan informasi diagnosa. Fungsi pada sistem berjalan dengan baik, dan kecepatan dalam menampilkan juga cepat. Hal ini sesuai dengan hasil penilaian kuesioner dari responden yang memiliki skor diatas $75 \%$.
Tabel 12 menunjukan hasil penilaian pengguna terhadap kehandalan sistem yang dibangun. Aspek yang dinilai adalah persentase error dan akurasi dalam diagnosa kerusakan skuter matik. Setelah dilakukan olah data, hasil polling pengguna menunjukan bahwa sistem cukup handal dalam memberikan informasi. Hal ini ditunjukan dengan rata-rata hasil kepuasan responden yang berada pada persentase diatas $70 \%$

\begin{tabular}{lll}
\multicolumn{3}{l}{ Tabel } \\
\hline No & Reliability & \\
\hline 1 & Sistem yang ada jarang terjadi error & Total \\
\hline 2 & $\begin{array}{l}\text { Informasi (hasil diagnosa) yang diberikan } \\
\text { dapat diandalkan/ dipercaya }\end{array}$ & $69 \%$ \\
\hline 3 & $\begin{array}{l}\text { Layanan sistem menyediakan informasi, } \\
\text { yang handal/ reliable }\end{array}$ & $71 \%$ \\
\hline $\mathbf{4}$ & $\begin{array}{l}\text { Sistem ini akurat dalam mendiagnosa } \\
\text { kerusakan skuter matik }\end{array}$ & $68 \%$ \\
\hline
\end{tabular}

Tabel 13 menunjukan hasil kepuasan pengguna setelah memakai aplikasi. Aspek yang dinilai adalah tampilan, layanan, dan kenyamanan pengguna. Hasil kepuasan pengguna pada aspek tersebut dinyatakan puas, karena rata-rata nilainya lebih dari $70 \%$.

Tabel 13. Hasil Kepuasan Pengguna Terhadap Hasil Diagnosa Sistem

\begin{tabular}{lll}
\hline No & $\begin{array}{l}\text { Kepuasan Terhadap Sistem Diagnosa } \\
\text { Kerusakan Skuter Matik }\end{array}$ & Total \\
\hline 1 & $\begin{array}{l}\text { Penilaian anda terhadap sistem pakar yang } \\
\text { digunakan saat ini dapat membantu dan }\end{array}$ & $73 \%$ \\
& memuaskan anda \\
\hline 2 & $\begin{array}{l}\text { Penilaian anda terhadap sistem pakar ini } \\
\text { dalam memberikan layanan secara tepat dan }\end{array}$ & $69 \%$ \\
& akurat \\
\hline 3 & $\begin{array}{l}\text { Penilaian anda terhadap perhatian yang } \\
\text { diberikan oleh penyedia sistem informasi }\end{array}$ & $71 \%$ \\
& $\begin{array}{l}\text { terhadap masalah-masalah yang sedang } \\
\text { dihadapi }\end{array}$ \\
\hline 4 & $\begin{array}{l}\text { Penilaian anda terhadap kemampuan sistem } \\
\text { pakar ini menyakinkan anda sehingga }\end{array}$ & $70 \%$ \\
& $\begin{array}{l}\text { membuat anda selalu menggunakan sistem } \\
\text { tersebut }\end{array}$ \\
\hline 5 & $\begin{array}{l}\text { Penilaian anda terhadap kemampuan sistem } \\
\text { pakar ini menyakinkan anda sehingga }\end{array}$ & $71 \%$ \\
& membuat anda akan merekomendasikannya \\
& kepada masyarakat luas \\
\hline
\end{tabular}

\section{KESIMPULAN}

Berdasarkan hasil analisa dan pembahasan dapat disimpulkan bahwa sistem yang dibangun dapat melakukan diagnosa kerusakan skuter matik dengan akurat. Hal ini dibuktikan melalui pengujian tingkat akurasi antara data real dengan data aplikasi. Berdasarkan perbandingan kedua data tersebut diperoleh prosentase akurasi sebesar 81,25 persen.

Berikutnya dari segi tampilan user interface, aplikasi yang dibangun memudahkan pengguna untuk menggunakan fitur-fitur 
dalam mendiagnosa kerusakan skutik. Hal tersebut dibuktikan melalui pengujian menggunakan kuesioner. Berdasarkan pengalaman yang dirasakan oleh 30 responden yang menggunakan aplikasi kerusakan skutik, diperoleh hasil bahwa aplikasi dapat bekerja dengan baik, kecepatan respon dalam menampilkan hasil diagnosa dapat diperoleh secara cepat dan akurat. Berdasarkan hasil kuesioner lebih dari 70\% merekomendasikan aplikasi diagnosa kerusakan skutik untuk disebarluaskan ke masyarakat luas.

\section{DAFTAR PUSTAKA}

[1] AISI, "Data Distribusi Sepeda Motor." [Online]. Available: http://www.aisi.or.id/statistic/. [Accessed: 11-May-2019].

[2] Kusrini, Konsep dan Aplikasi Sistem Pendukung Keputusan. Yogyakarta: Andi, 2007.

[3] R. Novhirtamely Kahar, "Penerapan Metode Fuzzy Multi Criteria Decision Making Pada Sistem Pendukung Keputusan Pemilihan Smartphone," Fortech (Journal Inf. Technol., vol. 1, no. 1, pp. 37-42, 2017.

[4] A. P. Lubis, P. Studi, and S. Komputer, "Penerapan Fuzzy Multi Criteria Decision Making untuk Kelinci Pedaging Unggul," J. Teknol. dan Sist. Inf., vol. 4, no. 2, 2018.

[5] Y. P. K. Kelen, "Pemilihan Wilayah Alternatif Terbaik Dengan Menggunakan Metode Multi Criteria Decision Making,” J. Ilmu Komput., vol. 1, no. 1, pp. 19-26, 2015.

[6] R. Rosnelly and R. Wardoyo, "Penerapan Fuzzy Multi Criteria Decision Making (FMCDM) untuk Diagnosis Penyakit Tropis," Semin. Nas. Inform. 2011, vol. 1, no. 1, pp. 21-26, 2011.

[7] APJII, "Penetrasi \& Perilaku Pengguna Internet Indonesia Tahun 2017," Jakarta, 2017.

[8] Z. Niswati, A. Paramita, and F. A. Mustika, "Aplikasi Fuzzy Logic dalam Diagnosa Penyakit Diabetes Mellitus pada Puskesmas di Jakarta Timur," J. Nas. Teknol. dan Sist. Inf., vol. 2, no. 3, pp. 21-30, 2016.

[9] F. A. Mustika and S. Sutrisno, "Model Evaluasi Kinerja Karyawan dengan Metode Fuzzy Sugeno pada Resto ABTL," STRING (Satuan Tulisan Ris. dan Inov. Teknol., vol. 1, no. 1, pp. 89-96, 2016.

[10] Marimin, Penalaran Fuzzy. Bogor: Departemen ilmu Komputer IPB, 2012.

[11] S. Y. Wang and C. F. Lee, "Fuzzy multi-criteria decision-making for evaluating mutual fund strategies," Appl. Econ., vol. 43, no. 24, pp. 3405-3414, 2011.

[12] M.-F. CHEN, G.-H. TZENG, and T.-I. TANG, "Fuzzy Mcdm Approach for Evaluation of Expatriate Assignments," Int. J. Inf. Technol. Decis. Mak., vol. 4, no. 2, pp. 277-296, 2005.

[13] S. Kusumadewi, I. Guswaludin, K. Sistem, P. Keputusan, and D. Support, FUZZY MULTI-CRITERIA DECISION MAKING, vol. 3, no. 1. 2005.

[14] A. Ramadhan, "Perbandingan K-Means dan Fuzzy CMeans untuk Pengelompokan Data User Knowledge Modeling," Semin. Nas. Teknol. Informasi, Komun. dan Ind. 9, pp. 18-19, 2017.

[15] R. Rustiyan and M. Mustakim, "Penerapan Algoritma Fuzzy C Means untuk Analisis Permasalahan Simpanan Wajib Anggota Koperasi," J. Teknol. Inf. dan Ilmu Komput., vol. 5, no. 2, p. 171, 2018.

\section{BIODATA PENULIS}

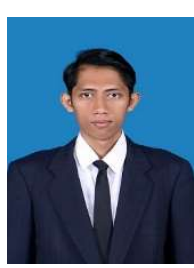

Afandi Nur Aziz Thohari, S.T., M.Cs. Lahir di Semarang pada tahun 1990 dan menyelesaikan sekolah dasar hingga pendidikan sarjana di tanah kelahiran. Memperoleh gelar sarjana dari Program S1 Teknik Komputer Universitas Diponegoro Semarang pada tahun 2013. Kemudian melanjutkan studi program pasca sarjana di Universitas Gadjah Mada dan mendapat gelar magister ilmu komputer pada tahun 2016. Saat ini penulis aktif sebagai pengajar di program studi S1 Rekayasa Perangkat Lunak IT Telkom Purwokerto.

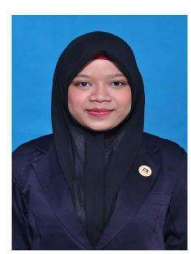

Rima Dias Ramadhani, S.Kom., M.Kom. Lahir di Semarang pada tahun 1993 dan menyelesaikan pendidikan sekolah dasar hingga sekolah menengah kejuruan di tanah kelahiran. Memperoleh gelar sarjana dari Program S1 Teknik Informatika Universitas Dian Nuswantoro Semarang pada tahun 2014. Kemudian melanjutkan studi pada tahun dan kampus yang sama dan memperoleh gelar magister komputer pada tahun 2015. Saat ini penulis aktif sebagai pengajar di program studi S1 Informatika IT Telkom Purwokerto. 